\title{
High prevalence of vitamin $D$ insufficiency and deficiency among patients with anorexia nervosa in Japan
}

\author{
M. Hotta
}

Received: 20 May 2014 / Accepted: 27 October 2014 / Published online: 20 November 2014

(C) International Osteoporosis Foundation and National Osteoporosis Foundation 2014

Dear Editor,

In their report in Osteoporosis International, Haagensen et al. presented that the prevalence of vitamin D deficiency is lower among adolescents with anorexia nervosa (AN) than among healthy controls in the USA [1] because more girls with AN take vitamin D supplements compared with healthy controls in that country.

We measured serum levels of 25-hydroxyvitamin D $(25(\mathrm{OH}) \mathrm{D})$ and intact parathyroid hormone $(\mathrm{iPTH})$ in 63 Japanese female patients with AN diagnosed according to DSM-5 (restricting type, $n=31$; binge eating/purging type, $n=32$ ) with an age of $27 \pm 8.7$ (mean \pm SD)years (range, 18 46) and a body mass index of $14.6 \pm 2.5 \mathrm{~kg} / \mathrm{m}^{2}$ (range, 9.920.1). Only 9 of the 63 patients with AN (14\%) showed serum $25(\mathrm{OH}) \mathrm{D}>30 \mathrm{ng} / \mathrm{mL}$, suggesting vitamin D sufficiency. Nine and 45 patients with AN were evaluated as vitamin D insufficiency $(30 \mathrm{ng} / \mathrm{mL}>25(\mathrm{OH}) \mathrm{D} \geq 20 \mathrm{ng} / \mathrm{mL}$ ) and vitamin $\mathrm{D}$ deficiency $(25(\mathrm{OH}) \mathrm{D}<20 \mathrm{ng} / \mathrm{mL})$, respectively. Only two patients were taking multivitamin supplements containing vitamin D2. Twenty of the 63 patients with AN showed increased serum levels of iPTH, indicating secondary hyperparathyroidism.

The lack of foods supplemented with vitamin D, recent trends toward avoiding sunbathing, and reductions in the consumption of seafood products are contributing to an increased prevalence of vitamin D insufficiency among the general

A reply to these comments can be found at doi: 10.1007/s00198-0142956-2.

\section{Hotta $(\square)$}

Health Services Center, National Graduate Institute for Policy Studies, 7-22-1 Roppongi, Minato-ku, Tokyo 106-8677, Japan e-mail: marihs@grips.ac.jp population in Japan [2]. Surprisingly, the rickets that seemed to be past illness increases again in Japan [3].

The Japanese medical system faces obstacles to vitamin D measurement and treatment because the cost of measuring serum $25(\mathrm{OH}) \mathrm{D}$ concentrations as a marker of vitamin $\mathrm{D}$ stores is not covered by the national health insurance scheme and therefore must be paid for by the patient. Physicians thus do not regularly measure $25(\mathrm{OH}) \mathrm{D}$, and vitamin D deficiency is often overlooked. Since vitamin D2 tablets are not available to prescribe in Japan, physicians must use $1 \alpha$-hydroxyvitamin D3 for patients with vitamin D deficiency.

In Japan, we have found patients with AN among both sexes at 9-10 years old in elementary schools. The point prevalence of AN among senior high school girls in Tokyo is about $0.26 \%$. Serum $25(\mathrm{OH}) \mathrm{D}$ should be measured in patients with $\mathrm{AN}$, and patients identified as vitamin D deficiency should receive vitamin D medication to prevent osteomalacia or osteoporosis.

Conflict of interest None.

\section{References}

1. Haagensen AL, Feldman HA, Ringelheim J, Gordon CM (2008) Low prevalence of vitamin $\mathrm{D}$ deficiency among adolescents with anorexia nervosa. Osteoporos Int 19:289-294

2. Yoshimura N, Muraki S, Oka H, Morita M, Yamada H, Tanaka S, Kawaguchi H, Nakamura K, Akune T (2013) Profiles of vitamin D insufficiency and deficiency in Japanese men and women: association with biological, environmental, and nutritional factors and coexisting disorders: the ROAD study. Osteoporos Int 24:2775-2787

3. Matsuo K, Mukai T, Suzuki S, Fujieda K (2009) Prevalence and risk factors of vitamin D deficiency rickets in Hokkaido, Japan. Pediatr Int 51:559-562 